\title{
Preparation of polyelectrolyte multilayer membranes by dynamic layer-by-layer process for pervaporation separation of alcohol/water mixtures
}

\author{
Guojun Zhang ${ }^{\mathrm{a}}$, Weiliang Gu ${ }^{\mathrm{a}}$, Shulan $\mathrm{Ji}^{\mathrm{a}}{ }^{\mathrm{a} *}$, Zhongzhou Liu ${ }^{\mathrm{b}}$, Yuelian Peng ${ }^{\mathrm{a}}$, Zhan Wang ${ }^{\mathrm{a}}$ \\ ${ }^{a}$ Center for Membrane Technology, College of Environmental and Energy Engineering, Beijing University of Technology, Beijing 100022, PR China \\ ${ }^{\mathrm{b}}$ Research Center for Eco-Environmental Sciences, Chinese Academy of Sciences, Beijing 100085, PR China \\ Received 19 October 2005; received in revised form 23 February 2006; accepted 27 February 2006 \\ Available online 16 June 2006
}

\begin{abstract}
In the past decades, the layer-by-layer (LBL) adsorption of oppositely charged polyelectrolytes has proven to be a promising method for the preparation of polyelectrolyte multilayer membranes. However, to obtain a good separation capability, LBL adsorption involved relatively long periods because 50-60 bilayers were normally required. The aim of this study was to develop such a new method that would allow simplification of the LBL procedure. LBL adsorption was proposed to proceed under a dynamic condition to prepare polyelectrolyte multilayer membranes. The polyacrylic acid (PAA) and polyethyleneimine (PEI) were alternatively deposited on polyethersulfone (PES) ultrafiltration support membrane under a pressure of $0.1 \mathrm{MPa}$. The polyelectrolyte multilayer membranes prepared by dynamic LBL process were compared with those prepared by the static LBL process for the pervaporation separation of water-ethanol mixture. The results suggested that a relatively high separation factor could be obtained with only four composite bilayers by using dynamic LBL process. The preparative conditions including bilayer number, filtration time of the first PAA layer, reaction time, ratio between polayanion and polycation concentrations, PAA molecular weight and salt addition were investigated. The pervaporation conditions such as feed temperature and water concentration in the feed were also evaluated. Under the temperature of $40^{\circ} \mathrm{C}$, the separation factor and the permeate flux of the polyelectrolyte multilayer membranes were about $1207 \mathrm{and} 140 \mathrm{~g} /\left(\mathrm{m}^{2} \mathrm{~h}\right), \mathrm{respectively}$. (C) 2006 Published by Elsevier B.V.
\end{abstract}

Keywords: Polyelectrolyte multilayer membranes; Dynamic layer-by-layer process; Polyacrylic acid (PAA); Polyethyleneimine (PEI); Pervaporation; Water/alcohol mixture

\section{Introduction}

Pervaporation has been considered as a cost-effective and energy-saving membrane-based technique for separating azeotropic, close-boiling, or aqueous organic mixtures [1]. In particular, great efforts have been made to develop effective membranes for the dewatering of low molecular weight alcohols such as ethanol. In the past decades, the layer-by-layer (LBL) adsorption of oppositely charged polyelectrolytes has proven to be a promising method for the preparation of ultrathin coatings of controlled thickness in the nanometer range [2-14]. This technique is based on the alternating adsorption of multiply charged cationic and anion species. The formation and proper-

\footnotetext{
* Corresponding author. Tel.: +86 1067392961 ; fax: +86 1067391983.

E-mail address: jshl@bjut.edu.cn (S. Ji).
}

ties of polyelectrolyte multilayer membranes using LBL method have been studied extensively in recent years [2-14]. By using different polyelectrolyte pairs, Tieke and co-workers [2-7] have prepared different kinds of polyelectrolyte multilayer membranes for pervaporation separation of alcohol/water mixtures. These polyelectrolyte pairs include poly(allylamine hydrochloride)/polystyrenesulfonate (PAH/PSS), poly(vinylamine)/poly(vinyl sulfate) (PVA/PVS), poly(ethyleneimine)/ poly(vinylsulfate) (PEI/PVS), poly(ethyleneimine)/polystyrenesulfonate (PEI/PSS), poly(allylamine hydrochloride)/poly(vinyl sulfate) (PAH/PVS), poly(allylamine hydrochloride)/ dextran sulfate (PAH/DEX), poly(diallyldimethylammonium chloride)/polystyrenesulfonate (PDADMAC/PSS), poly(4-vinylpyridine)/polystyrenesulfonate (P4VP/PSS) and chitosan/ polystyrenesulfonate (CHI/PSS). Merie-Haack et al. [8] also reported other polyelectrolyte pairs, such as poly(acrylic acid)/poly(ethylenimine) (PAAc/PEI), poly(ethylenimine) 
/alginic acid (PEI/Alg), poly(diallyldimethylammoniumchloride)/poly(acrylic acid) (PDADMAC/PAAc), chitosan/alginic acid (Chi/Alg) and chitosan/poly(acrylic acid) (Chi/PAAc). In addition to the materials, performance of these membranes depends strongly on the bilayer number. It was noted from Tieke and co-workers studies [2-7] that as many as 60 bilayers had to be deposited to obtain membranes with sufficient properties in LBL adsorption process. This means LBL is a time-consuming preparation method. Therefore, it is necessary to seek for a further concise procedure for the preparation for polyelectrolyte multilayer membranes.

Dynamically formed membranes (DFM) are formed by filtration through a porous support of a dilute solution containing specific membrane-forming materials [15]. Due to the advantages of abundant membrane material sources and a simple membranemaking technique, DFM is regarded as a very promising separation membrane [16]. However, the previous studies on DFM mainly focused on the preparation of UF and MF membranes [15-21]. Relatively few works have dealt with the preparation of pervaporation membranes using dynamically formed method. In our laboratory, we had previously reported to use dynamically formed method to prepare poly(vinyl alcohol) UF membranes with good anti-fouling characteristics [17].

Based on the past successful experiences in dynamic UF membrane, we propose to combine dynamically formed method with layer-by-layer adsorption for preparing polyelectrolyte carried out under the different operating conditions by changing feed temperature and water content in the feed solutions.

\section{Experimental}

\subsection{Materials}

Fully hydrolyzed PAA powder having average molecular weight of 4,000,000 and 450,000 was obtained from Aldrich. Linear poly(ethyleneimine) (PEI) with the molecular weight of 60,000 was purchased from ACROS. The flat-sheet ultrafiltration (UF) membranes used as the support membranes were purchased from AEEM. The molecular weight cut-off of the support UF membrane was 20,000.

\subsection{Membrane preparation by static LBL process}

PAA and PEI were dissolved in aqueous medium in a concentration of $0.05 \mathrm{wt} \%$ and $0.5 \mathrm{wt} \%$. The polyelectrolyte membranes were prepared upon alternate adsorption of cationic and anionic polyelectrolytes on a porous PES supporting membrane. In each dipping step, a polyelectrolyte layer is adsorbed under reversal of the surface charge so that in the next dipping step a polyelectrolyte layer of opposite charge can be adsorbed. In this way, multilayer membranes were prepared. Dipping time in the individual solutions was $20 \mathrm{~min}$. The polyion complex between PAA and PEI was formed according to the following equation:

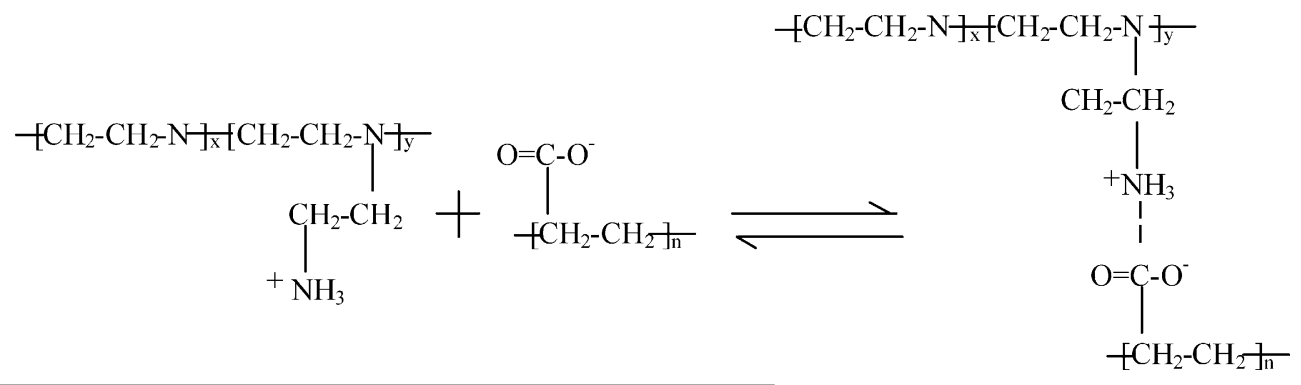

multilayer membranes in this study. It was expected that the non-porous separation bilayers could be formed within a short period by means of this dynamic coating method and in turn allow simplification of the LBL procedure. The effects of bilayer numbers, filtration time of the first PAA layer, reaction time, ratio between polyanion and polycation concentrations, PAA molecular weight and salt addition on membrane performance were investigated. The pervaporation measurements were also

\subsection{Membrane preparation by dynamic $L B L$ process}

As shown in Fig. 1, the preparation of polyelectrolyte multilayer membranes was carried out by using a $50 \mathrm{ml}$ stirred dead-ended filtration cell with approximately $79 \mathrm{~cm}^{2}$ membrane area. Aqueous PAA and PEI solutions were prepared by dissolving the polymer in distilled water completely and stirred

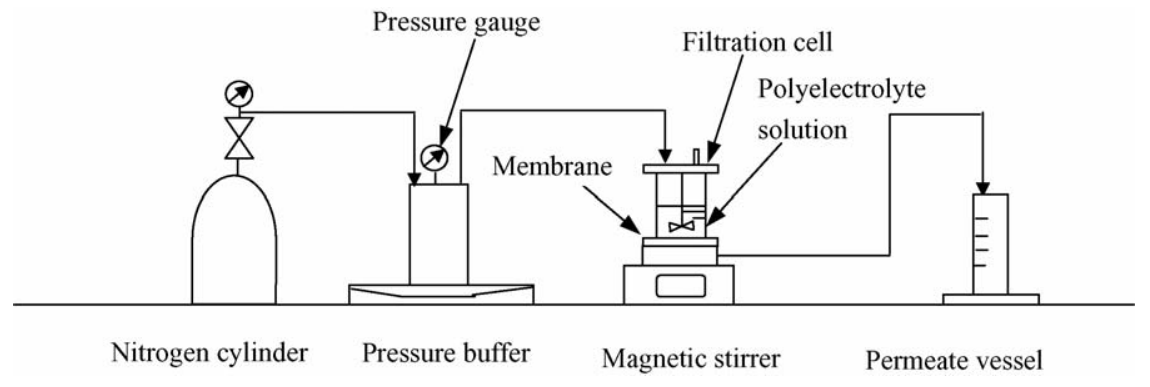

Fig. 1. Dead-end filtration cell for preparation of polyelectrolyte multilayer membranes. 
until homogeneous, respectively. The dynamic membrane was accomplished by filtrating the polyanion and polycation alternatively during a pre-determined period of filtration. The following steps were orderly carried out: (a) PAA solution was poured into the stirred cell in which a support membrane had been loaded, and was pressured through the membrane under a pressure of $0.1 \mathrm{MPa}$ by using a nitrogen cylinder. (b) The membrane was taken out, briefly rinsed with de-ionized water for approximately $5 \mathrm{~min}$ and dried in an oven at $50{ }^{\circ} \mathrm{C}$ for a pre-determined period (do note the membrane was directly dried only in the formation of the first bilayer). (c) PEI solution was poured into the stirred cell and pressured under a pressure of $0.1 \mathrm{MPa}$ for a predetermined period. (d) The same way as (b). Steps (a)-(d) were repeated up to the pre-determined times. Upon the formation of polyelectrolyte multilayers membranes, they were stored for pervaporation experiments.

\subsection{Pervaporation experiments}

The membranes were characterized by the pervaporation of alcohol/water mixtures $(95: 5 \mathrm{~g} / \mathrm{g})$. The pervaporation measurements were carried out in our laboratory using a home-made apparatus, which is shown in Fig. 2. The membrane cell had an effective membrane area of $28.3 \mathrm{~cm}^{2}$. The permeate was condensed in liquid nitrogen traps. The experiments were carried out at a down-stream pressure of $100 \mathrm{~Pa}$ by vacuum pump. Fluxes were determined by measuring the weight of liquid collected in the cold traps during a certain time under steady-state conditions. The composition of the collected permeate was determined by gas chromatography (GC-14C, SHIMADZU). The separation factor was calculated from the quotient of the weight ratio of water and alcohol in the permeate, $Y_{\mathrm{HOH}} / Y_{\mathrm{ROH}}$, and in the feed, $X_{\mathrm{HOH}} / X_{\mathrm{ROH}}$ :

$\alpha=\frac{Y_{\mathrm{HOH}} / Y_{\mathrm{ROH}}}{X_{\mathrm{HOH}} / Y_{\mathrm{ROH}}}$

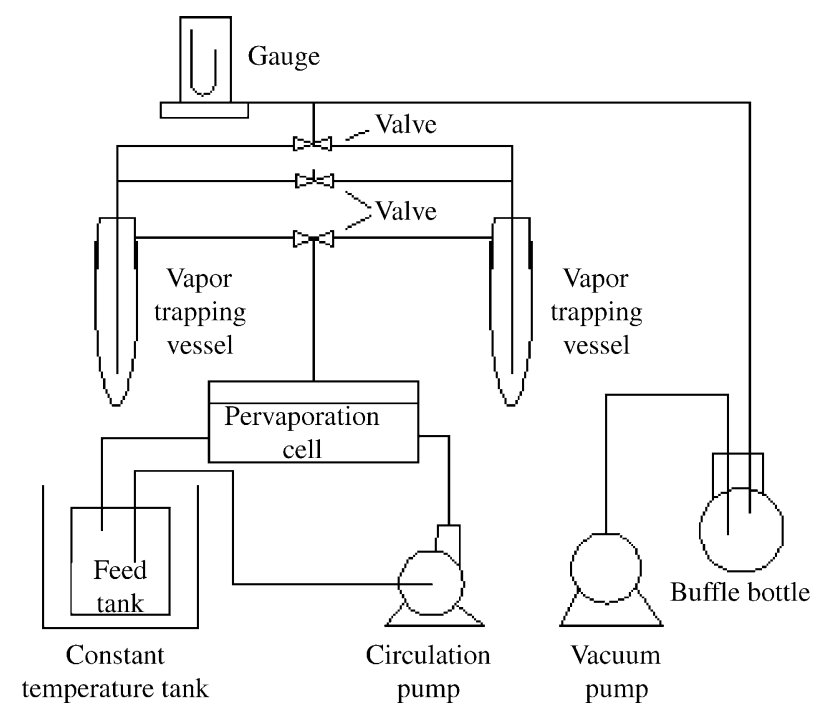

Fig. 2. Experimental apparatus for pervaporation evaluation.

\subsection{TOC and FESEM experiments}

A total organic carbon (TOC) analyzer (TOC-V $\mathrm{CPH}_{\mathrm{CP}}$, SHIMADZU) was used to determine the TOC values of PAA feed solution and UF permeate in the first filtration. A field emission scanning electron microscopy (FESEM) (Hitachi-4300, Japan) was used to observe the top surface and cross-section of the polyelectrolyte multilayer membranes obtained. All membrane samples were dried under vacuum, fractured in liquid nitrogen and gold-coated before observation.

\section{Results and discussion}

\subsection{Advantage of dynamic $L B L$ process over static $L B L$ process}

To prepare a membrane with good pervaporation performance, 50-60 pair numbers were usually required to deposit on the support layers in the studies of Tieke and co-workers [2-7]. In order to simplify this procedure, the dynamically formed method was proposed to combine with LBL technique in this study. Table 1 shows the performance of the pervaporation membranes by using static and dynamic LBL processes. It was noted from Table 1 that the separation factor could reach 1207 by dynamically depositing only four bilayers on the support membrane. As a comparison, the separation factor was only 18 when the four bilayers were formed by static LBL process. The possible reason was that the uniform and integrated separation layers could be formed much more easily during the dynamic LBL process compared with the static LBL process. It is well known that UF and MF support membranes have their own pore diameter distribution, which would lead to different permeate rates at different places when the polyions solution was pressurized. Under a certain pressure, the polyanion and polycation solutions were prone to aggregate at the places with higher permeate rate (at larger pore diameter). These effects would level off the support surface by forming the polyion complex, seal the membrane pores and form more uniform layers within only a few pairs. Meanwhile, the formed bilayers under the pressure were more compacted than those without pressure. Therefore, the dynamic LBL process is relatively simple and offers some advantages over the static LBL process, including short preparation period, saving of preparation solutions and getting better performance of the dynamic membrane. However, it should be pointed out that the

Table 1

The pervaporation performance of polyelectrolyte multilayer membranes prepared by two methods

\begin{tabular}{lcc}
\hline Preparation method & Dynamic LBL & Static LBL \\
\hline EtOH content in feed solution $(\%)$ & 95 & 95 \\
Water content in permeate $(\%)$ & 98.45 & 48.07 \\
Permeate flux, $J\left(\mathrm{~g} / \mathrm{m}^{2} \mathrm{~h}\right)$ & 140 & 374 \\
Separation factor, $\alpha$ & 1207 & 18
\end{tabular}

Preparative conditions: dynamic pressure $=0.1 \mathrm{MPa}, 10 \mathrm{~min}$ filtration time of the first PAA layer, $20 \mathrm{~min}$ reaction time, $[\mathrm{PAA}]=0.05 \mathrm{wt} \%,[\mathrm{PEI}]=0.5 \mathrm{wt} \%$, $[\mathrm{PAA}] /[\mathrm{PEI}]=1 / 10$, four bilayers and $25^{\circ} \mathrm{C}$; pervaporation conditions: feed temperature $40^{\circ} \mathrm{C}$, down-stream pressure $100 \mathrm{~Pa}$ and $\mathrm{EtOH}$ content in feed solution $95 \mathrm{wt} \%)$. 


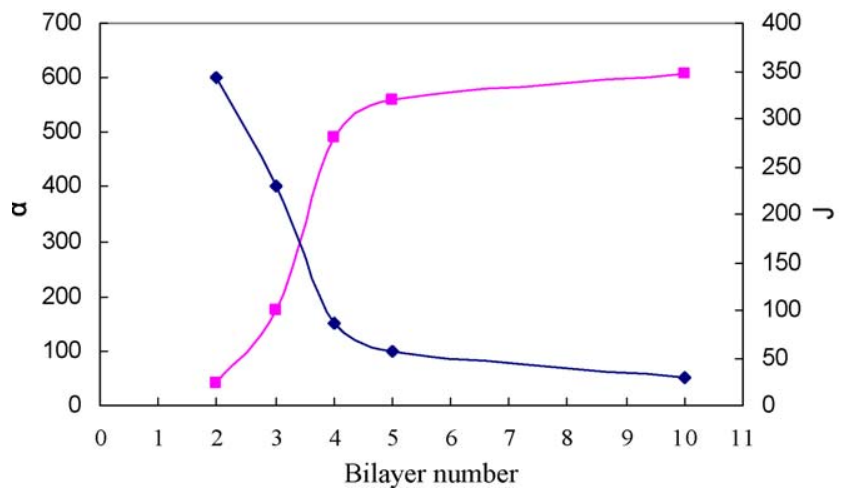

Fig. 3. Effect of polyion bilayer numbers on separation factor and flux (preparative conditions: applied pressure $=0.1 \mathrm{MPa}, 10 \mathrm{~min}$ filtration time of the first PAA layer, 20 min reaction time, PAA molecular weight 4,000,000, [PAA] $=0.05 \mathrm{wt} \%$ and $[\mathrm{PEI}]=0.5 \mathrm{wt} \%$; pervaporation conditions: feed temperature $25^{\circ} \mathrm{C}$, permeate pressure $100 \mathrm{~Pa}$ and $\mathrm{EtOH}$ content in feed solution $95 \mathrm{wt} \%$ ).

reproducibility of the membrane prepared by dynamic LBL is still an issue that remains to be resolved.

\subsection{Effect of polyion bilayer numbers}

The polyion bilayer numbers usually plays an important role during the LBL process. The membranes coated with different numbers of PAA/PEI layers are plotted in Fig. 3. The separation factors obtained at one to three pairs were much lower than those obtained at pairs of four and five. However, the separation factors obtained at four and five pairs were relatively high. The higher separation factor associated with five pairs (Fig. 3) led to the slightly lower fluxes obtained. Comparing the results obtained from 4 bilayers and 10 bilayers, the 10 bilayers did not confer much additional benefit for the improvement of separation factor. In contrast, the higher bilayers rendered flux to decrease significantly. These results indicated that four pairs are sufficient to get a relatively high separation factor and flux. In view of this, four pairs were selected for subsequent experiments.

\subsection{Effect of the filtration time of the first PAA layer}

Fig. 4(a) shows the profiles of PES UF membrane flux with the filtration time. It is noted that the flux of the UF support membrane decreased very rapidly at the initial filtration time. A relatively stable flux of about $0.75-0.85 \mathrm{~g} / \mathrm{min}$ (applied pressure $=0.1 \mathrm{MPa}$ and temperature $=25^{\circ} \mathrm{C}$ ) was obtained when filtration time was maintained at $10-12 \mathrm{~min}$, which indicated that a steady gel layer formed on the top surface of support membrane. In the succedent filtration of PEI solution, no permeation flux was found. Obviously, in the dynamic LBL process, the polyion complex between PAA and PEI was possibly formed only on the top side of the PES support. In order to further verify if the PAA can be retained $100 \%$ in the first filtration, the TOC values of the feed and permeate were also determined. The TOC values of $0.05 \mathrm{wt} \%$ PAA feed solution and UF permeate were $252 \mathrm{mg} / 1$ and $16.2 \mathrm{mg} / \mathrm{l}$, respectively. This suggested $93.57 \%$ PAA was retained while only a few PAA molecules may enter into the pores of the support membrane.
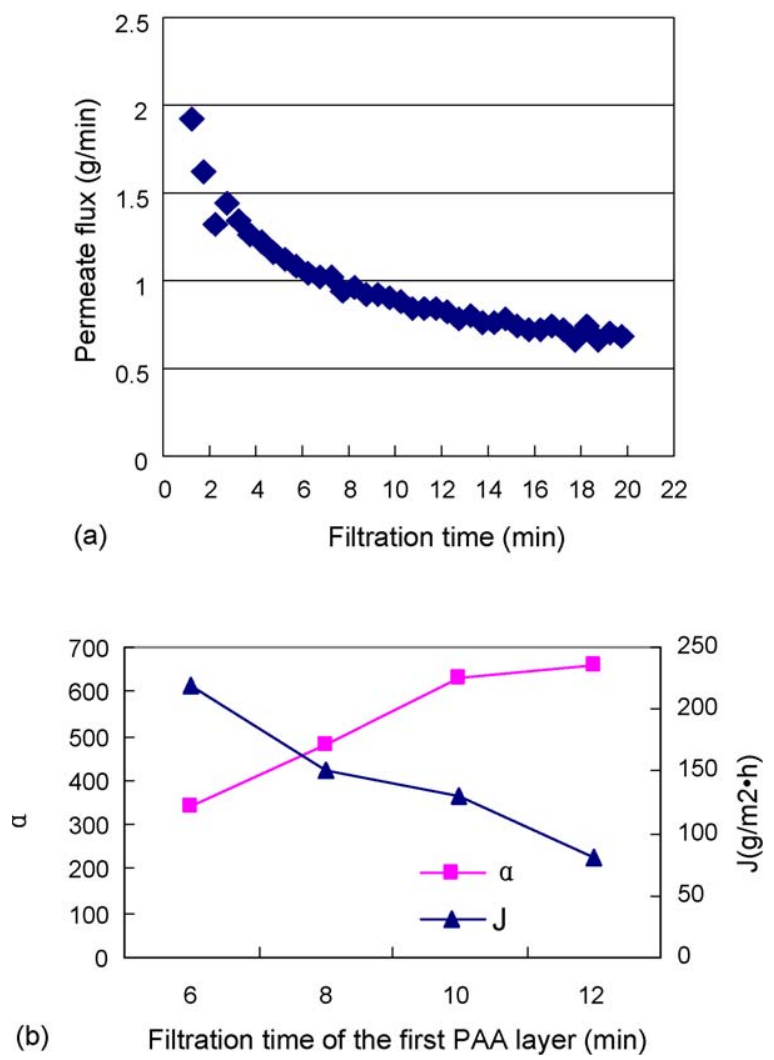

Fig. 4. (a) Profiles of PES UF membrane flux with the filtration time (applied pressure $=0.1 \mathrm{MPa}$ and temperature $=25^{\circ} \mathrm{C}$ ). (b) Effect of the filtration time of the first PAA layer on pervaporation performance (preparative conditions: applied pressure $=0.1 \mathrm{MPa}, 20 \mathrm{~min}$ reaction time, $\mathrm{PAA}$ molecular weight $4,000,000,[\mathrm{PAA}]=0.05 \mathrm{wt} \%,[\mathrm{PEI}]=0.5 \mathrm{wt} \%$ and four bilayers; pervaporation conditions: feed temperature $25^{\circ} \mathrm{C}$, down-stream pressure $100 \mathrm{~Pa}$ and $\mathrm{EtOH}$ content in feed solution $95 \mathrm{wt} \%$ ).

The effect of the filtration time of the first PAA layer on pervaporation membrane performance is shown in Fig. 4(b). It was noted from Fig. 4(b) that the separation factors increased with the PAA filtration time while the flux decreased. However, relatively high separation factor and steady flux could be obtained when the steady gel layer formed on the top surface of support membrane at $10-12 \mathrm{~min}$. It was thought that the thickness of the first layer was strongly dependant on the filtration time and influenced the pervaporation performance. Recognizing this, a 10 min filtration time for the first layer was adopted for subsequent study. Do note no UF flux was determined from the second round filtration. Thus, the effect of reaction time between PAA and PEI was also investigated in the following study.

\subsection{Effect of the reaction time}

As outlined earlier, in the dynamic LBL process, the PAA was firstly deposited on the support membrane and formed a gel layer followed by filtrating PEI solution. Then the PAA and PEI were filtrated alternatively. Obviously, the reaction time between PAA and PEI would play an important role in the formation of polyions complex. Table 2 shows the relationship between pervaporation performance and the reaction time. It is noted from the table that the separation factor obtained at 20 min reaction 
Table 2

Effects of the reaction time on pervaporation performance of polyelectrolyte multilayer membranes

\begin{tabular}{llllr}
\hline Reaction time (min) & $\begin{array}{l}\text { EtOH content in feed } \\
\text { solution }(\mathrm{wt} \%)\end{array}$ & $\begin{array}{l}\text { Water content in } \\
\text { permeate }(\mathrm{wt} \%)\end{array}$ & $\begin{array}{l}\text { Separation } \\
\text { factor, } \alpha\end{array}$ \\
\hline 10 & 95 & 95.1 & 369 & \multicolumn{1}{c}{$\begin{array}{l}\text { Permeate flux, } \\
\left(\mathrm{g} / \mathrm{m}^{2} \mathrm{~h}\right)\end{array}$} \\
20 & 95 & 98.1 & 981 & 110 \\
30 & 95 & 95.4 & 394 & 80 \\
45 & 95 & 81.5 & 84 & 100
\end{tabular}

Preparative conditions: dynamic pressure $=0.1 \mathrm{MPa}, 10 \mathrm{~min}$ filtration time of the first PAA layer, $[\mathrm{PAA}]=0.05 \mathrm{wt} \%,[\mathrm{PEI}]=0.5 \mathrm{wt} \%$, $[\mathrm{PAA}] /[\mathrm{PEI}]=1 / 10$, four bilayers and $25^{\circ} \mathrm{C}$; pervaporation conditions: feed temperature $25^{\circ} \mathrm{C}$, down-stream pressure $100 \mathrm{~Pa}$ and EtOH content in feed solution $95 \mathrm{wt} \%$ ).

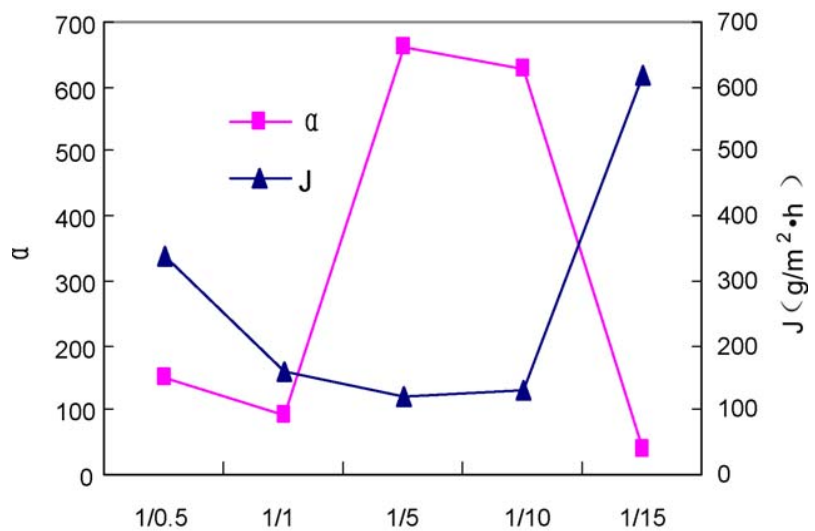

Ratio between polyanion and polycation concentrations

Fig. 5. Profiles of pervaporation membrane performance with the ratio between polyanion and polycation concentrations (preparative conditions: applied pressure $=0.1 \mathrm{MPa}, 10 \mathrm{~min}$ filtration time of the first PAA layer, 20 min reaction time, PAA molecular weight $4,000,000,[\mathrm{PAA}]=0.05 \mathrm{wt} \%,[\mathrm{PEI}]=0.5 \mathrm{wt} \%$ and four bilayers; pervaporation conditions: feed temperature $25^{\circ} \mathrm{C}$, permeate pressure $100 \mathrm{~Pa}$ and $\mathrm{EtOH}$ content in feed solution $95 \mathrm{wt} \%$ ).

was much higher than those obtained at 10,30 and $40 \mathrm{~min}$. It is noted that $10 \mathrm{~min}$ was not sufficient for reaction. Since PAA is soluble in water, exceeding contact between PAA and PEI solution may result in the swelling of PAA and destroy the structure of polyion complex formed and in turn the decline of separation factor.

\subsection{Effect of the ratio between polyanion and polycation concentrations}

Fig. 5 shows the profiles of pervaporation membrane performance with the ratio between polyanion and polycation concentrations. The ratio between polyanion and polycation con- centrations of $1 / 5-1 / 10$ were found to be appropriate, achieving the separation factors of around 650 . When the ratio is at the range of $1 / 0.5-1 / 5$ or $1 / 10-1 / 15$, performance declined sharply (Fig. 5). These results suggest that an appropriate value of the ratio between polyanion and polycation was existed. The regular polyions complex was normally ideal to achieve high separation factor. Exceeding PAA or PEI may cause the mixture of polyions complex and polyanion/or polycation, which led to the decline of separation factor.

\subsection{Effects of PAA molecular weight and salt addition}

The effect of PAA molecular weight was evaluated by using the PAA having average molecular weight of 4,000,000 and 450,000 . Table 3 shows the effect of PAA molecular weight on pervaporation membrane performance. It is noted that the high molecular PAA resulted in high separation factor. The possible reason was that the high molecular weight PAA facilitated the formation of the first gel layer and resulted in more compact polyion complex layers. Besides the PAA molecular weight, the ionic strength of the polyelectrolyte solutions used for preparation of the membrane is other important factor influencing the separation behaviour. Addition of salt to the polyelectrolyte solution strongly reduces the mutual electrostatic repulsion of the polymer chains. In Table 3, the separation behaviour of PAA/PEI membranes prepared from salt-free or salt-containing solution is compared. It is noted that the salt addition has negative effects on the separation factors. For example, membranes even show a decrease of the separation factor from 1207 to 8 .

\subsection{Membrane micrograph}

The top surface and cross-section morphologies of the layerby-layer films of PAA/PEI were observed by FESEM. Here, the

Table 3

Effects of PAA molecular weight and salt addition

\begin{tabular}{|c|c|c|c|c|}
\hline Preparative conditions & $\begin{array}{l}\text { EtOH content in feed } \\
\text { solution (wt } \%)\end{array}$ & $\begin{array}{l}\text { Water content in } \\
\text { permeate (wt } \%)\end{array}$ & $\begin{array}{l}\text { Permeate flux, } J \\
\left(\mathrm{~g} / \mathrm{m}^{2} \mathrm{~h}\right)\end{array}$ & $\begin{array}{l}\text { Separation } \\
\text { factor, } \alpha\end{array}$ \\
\hline PAA (MW: 4,000,000)/PEI (MW: 60,000) & 95 & 98.45 & 140 & 1207 \\
\hline PAA (MW: 450,000)/PEI (MW: 60,000) & 95 & 35.56 & 3670 & 11 \\
\hline PAA (MW: $4,000,000)+0.1 \mathrm{~mol} / 1 \mathrm{NaCl} / \mathrm{PEI}(\mathrm{MW}: 60,000)$ & 95 & 28.97 & 2840 & 8 \\
\hline
\end{tabular}

Preparative conditions: dynamic pressure $=0.1 \mathrm{MPa}, 10 \mathrm{~min}$ filtration time of the first PAA layer, $20 \mathrm{~min}$ reaction time, four bilayers, $[\mathrm{PAA}]=0.05 \mathrm{wt} \%$, $[\mathrm{PEI}]=0.5 \mathrm{wt} \%,[\mathrm{PAA}] /[\mathrm{PEI}]=1 / 10$ and $25^{\circ} \mathrm{C}$; pervaporation conditions: feed temperature $40^{\circ} \mathrm{C}$, down-stream pressure $100 \mathrm{~Pa}$ and EtOH content in feed solution $95 \mathrm{wt} \%)$. 

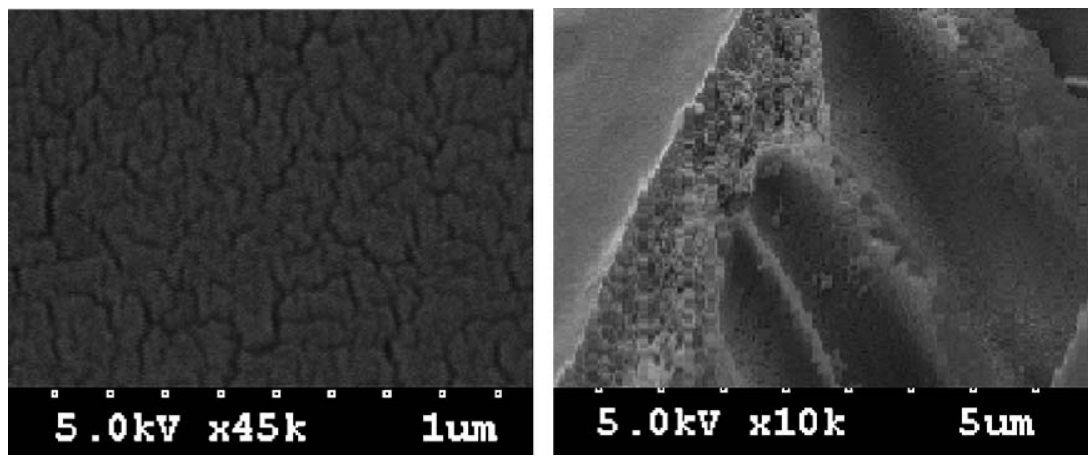

Fig. 6. (a) Field emission scanning electron micrograph of the top surface of polyelectrolyte multilayer membrane prepared by dynamic LBL process. (b) Field emission scanning electron micrograph of cross-section of polyelectrolyte multilayer membrane prepared by dynamic LBL process (preparative conditions: applied pressure $=0.1 \mathrm{MPa}, 10 \mathrm{~min}$ filtration time of the first PAA layer, $20 \mathrm{~min}$ reaction time, PAA molecular weight $4,000,000,[\mathrm{PAA}]=0.05 \mathrm{wt} \%,[\mathrm{PEI}]=0.5 \mathrm{wt} \%$, $[\mathrm{PAA}] /[\mathrm{PEI}]=1 / 10$ and four bilayers).

FESEM images of the layer-by-layer films with four bilayers are shown in Fig. 6. The results show that the morphology of the film produced was very smooth and uniform. The composite layer was cross-linked very well with the support membranes.

\subsection{Effect of feed temperature}

Fig. 7 shows the effects of temperature of alcohol/water mixture on pervaporation performance. As expected, the flux increased with increasing feed temperature (Fig. 7(a)). This is due to the increases in the water vapor pressure of feed side and the diffusion coefficients. The variation of flux with feed temperature fit well for Arrhenius law $\left(J=J_{0} \times \exp \left(-E_{\mathrm{M}} / R T\right)\right.$ (Fig. 7(a)) [22-25]. The effects of feed temperature on pervapo-

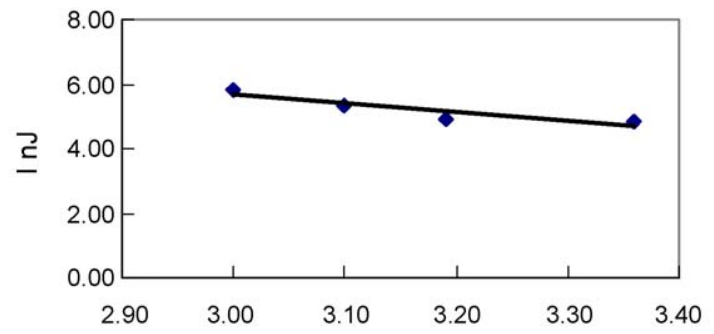

(a) $1 / \mathrm{T}\left(10^{3} \mathrm{~K}^{-1}\right)$

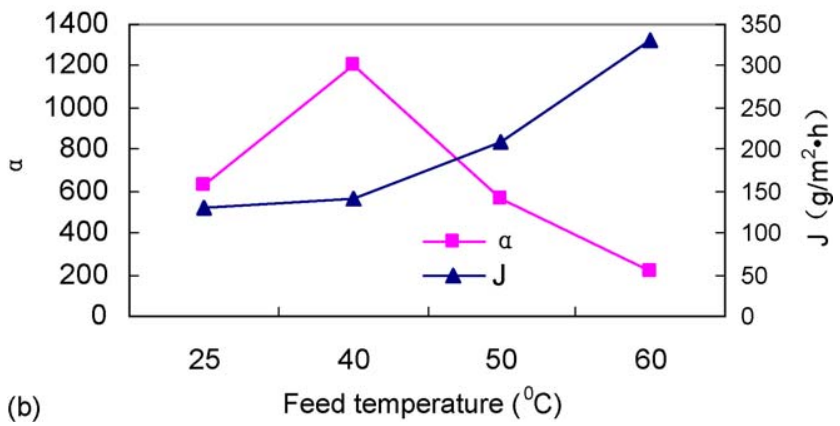

Fig. 7. (a and b) Effect of feed temperature on pervaporation performance (preparative conditions: applied pressure $=0.1 \mathrm{MPa}, 10 \mathrm{~min}$ filtration time of the first PAA layer, 20 min reaction time, PAA molecular weight 4,000,000, $[\mathrm{PAA}]=0.05 \mathrm{wt} \%,[\mathrm{PEI}]=0.5 \mathrm{wt} \%,[\mathrm{PAA}] /[\mathrm{PEI}]=1 / 10$ and four bilayers; pervaporation conditions: permeate pressure $100 \mathrm{~Pa}$ and $\mathrm{EtOH}$ content in feed solution $95 \mathrm{wt} \%$ ). ration performance were relatively complicated. Most polyions membrane pervaporation was accorded with Erying theory. However, in this study, a peak value of separation factor occurred at $40^{\circ} \mathrm{C}$. In pervaporation of polyelectrolyte multilayer membranes, diffusivity selectivity dominates the total pervaporation selectivity and the diffusivity selectivity is correlated with fractional free volume for the membranes. When the feed temperature was lower than $40^{\circ} \mathrm{C}$, the increase in diffusivity selectivity of water was more significant than the change of alcohol, which resulted in the increase in separation factor [22-25]. Separation factor declined sharply when feed temperature increased to the range of $40-60^{\circ} \mathrm{C}$ (Fig. 7(a)). The possible reason was that the significant swellings of PAA and polyion complex occurred at this feed temperature range.

\subsection{Effect of water content in feed solution}

In order to investigate the effect of water content in feed solution on membrane performance, the water content in feed solution was varied from 5 to $50 \%$. The pervaporation evaluation duration was $4 \mathrm{~h}$ at each of the water content investigated. Fig. 8

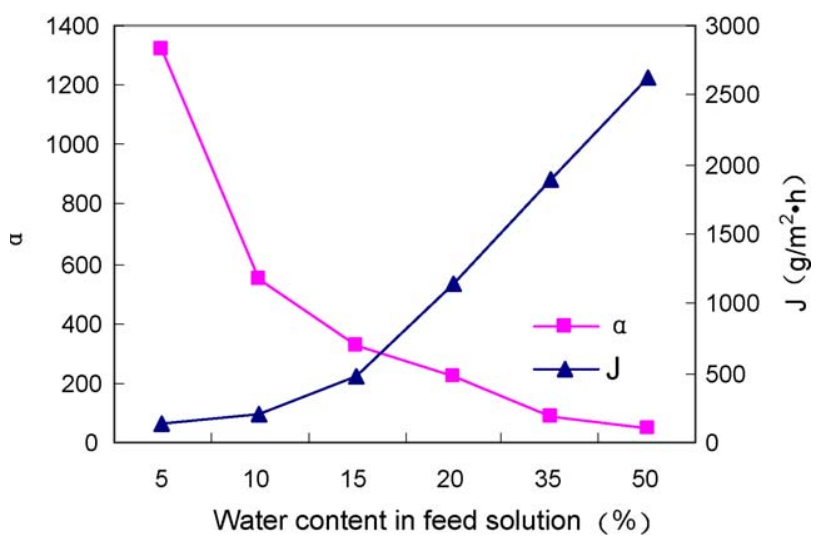

Fig. 8. Effect of water content in feed solution on pervaporation performance (preparative conditions: applied pressure $=0.1 \mathrm{MPa}, 10 \mathrm{~min}$ filtration time of the first PAA layer, $20 \mathrm{~min}$ reaction time, PAA molecular weight 4,000,000, $[\mathrm{PAA}]=0.05 \mathrm{wt} \%,[\mathrm{PEI}]=0.5 \mathrm{wt} \%,[\mathrm{PAA}] /[\mathrm{PEI}]=1 / 10$ and four bilayers; pervaporation conditions: feed temperature $40^{\circ} \mathrm{C}$, down-stream pressure $100 \mathrm{~Pa}$ and EtOH content in feed solution $95 \mathrm{wt} \%$ ). 
shows the relationship between pervaporation performance and water content in feed solution. It was noted that separation factor declined rapidly with increasing water content in feed solution while permeate flux increased. This is because, to some extent, the swelling of membrane occurred. However, the water content in permeate determined by GC was still maintained at $98.03 \%$ even the water content increased to $50 \%$ in feed solution. This suggested that the polyelectrolyte multilayer membranes prepared by dynamic LBL process could be applied within a relatively wide band of alcohol/water mixtures.

\section{Conclusions}

A uniform membrane of PAA/PEI was prepared by the dynamic layer-by-layer deposition technique. By comparing membrane prepared by static and dynamic LBL processes, it was found that good pervaporation performance could be easily prepared by depositing only four bilayers on support membranes using dynamic LBL process (under a pressure of $0.1 \mathrm{MPa}$ ). As a comparison, $50-60$ bilayers were usually required in the static LBL process. This finding suggests that dynamic LBL process offers some advantages over the static LBL process, such as relatively simple assembly, short preparation period and saving of preparation solutions, especially better pervaporation performance. In relation to the PAA/PEI composite membranes, a suitable PAA/PEI ratio was $1 / 5-1 / 10$ with a number of four bilayers. The molecular weight of PAA was 4,000,000. The corresponding filtration time of the first PAA layer range was $10 \mathrm{~min}$ while the reaction time was $20 \mathrm{~min}$. Given these conditions, the separation factor and the permeate flux were about 1207 and $140 \mathrm{~g} /\left(\mathrm{m}^{2} \mathrm{~h}\right)\left(40^{\circ} \mathrm{C}\right)$, respectively. In addition, these membranes were evaluated within a wide range of feed temperature and water content in feed solution. The water content in permeate could be maintained around $98.0 \%$, even the water content increased to $50 \%$ in feed solution.

\section{Acknowledgements}

This work was supported by the National Basic Research Program of China (No. 2003CB615701) and the Start-up funds for Ph.D. holders, Beijing University of Technology (127(VA)00173, 52005013200501).

\section{References}

[1] B. Smitha, D. Suhanya, S. Sridhar, M. Ramakrishna, Separation of organic-organic mixtures by pervaporation-a review, J. Membr. Sci. 241 (2004) 1-21.

[2] L. Krasemann, A. Toutianoush, B. Tieke, Self-assembled polyelectrolyte multilayer membranes with highly improved pervaporation separation of ethanol/water mixtures, J. Membr. Sci. 181 (2001) 221-228.

[3] A. Toutianoush, B. Tieke, Pervaporation separation of alcohol/water mixtures using self-assembled polyelectrolyte multilayer membranes of high charge density, Mater. Sci. Eng., C 22 (2002) 459-463.
[4] A. Toutianoush, L. Krasemann, B. Tieke, Polyelectrolyte multilayer membranes for pervaporation separation of alcohol/water mixtures, Colloids Surf. A 198-200 (2002) 881-889.

[5] F.v. Ackern, L. Krasemann, B. Tieke, Ultrathin membranes for gas separation and pervaporation prepared upon electrostatic self-assembly of polyelectrolytes, Thin Solid Films 327-329 (1998) 762-766.

[6] A. Toutianoush, B. Tieke, Selective transport and incorporation of highly charged metal and metal complex ions in self-assembled polyelectrolyte multilayer membranes, Mater. Sci. Eng. C 22 (2002) 135-139.

[7] R.v. Klitzing, B. Tieke, Polyelectrolyte membranes, Adv. Polym. Sci. 165 (2004) 177-210

[8] J. Meier-Haack, W. Lenk, D. Lehmann, K. Lunkwitz, Pervaporation separation of water/alcohol mixtures using composite membranes based on polyelectrolyte multilayer assemblies, J. Membr. Sci. 184 (2) (2001) 233-243.

[9] D. Wakizaka, T. Fushimi, H. Ohkita, S. Ito, Hole transport in conducting ultrathin films of PEDOT/PSS prepared by layer-by-layer deposition technique, Polymer 45 (2004) 8561-8565.

[10] J. Chen, G. Luo, W. Cao, The study of layer-by-layer ultrathin films by the dynamic contact angle method, J. Colloid Interface Sci. 238 (2001) $62-69$.

[11] M.K. Ram, M. Adami, P. Faraci, C. Nicolini, Physical insight in the insitu self-assembled films of polypyrrole, Polymer 41 (2000) 7499-7509.

[12] Y. Lvov, K. Ariga, M. Onda, I. Ichinose, T. Kunitake, A careful examination of the adsorption step in the alternate layer-by-layer assembly of linear polyanion and polycation, Colloids Surf. A 146 (1999) 337-346.

[13] J. Chu, X. Li, Tang J., Studies on poly(ethylenimine)/purple membrane multilayer films fabricated by layer-by-layer self-assembly, Colloids Surf. A 257-258 (2005) 41-45.

[14] D.W. Kim, H. Choi, C. Lee, A. Blumstein, Y. Kang, Investigation on methanol permeability of Nafion modified by self-assembled claynanocomposite multilayers, Electrochim. Acta 50 (2004) 659-662.

[15] J.Y. Wang, M.C. Liu, C.J. Lee, K.S. Chou, Formation of dextran-Zr dynamic membrane and study on concentration of protein hemoglobin solution, J. Membr. Sci. 162 (1999) 45-55.

[16] B. Cai, H. Ye, L. Yu, Preparation and separation performance of a dynamically formed $\mathrm{MnO}_{2}$ membrane, Desalination 128 (2000) 247-256.

[17] N. Li, Z.Z. Liu, S.G. Xu, Dynamically formed poly(vinyl alcohol) ultrafiltration membranes with good anti-fouling characteristics, J. Membr. Sci. 169 (2000) 17-28.

[18] C.C. Chen, B.H. Chiang, Formation and characteristics of zirconium ultrafiltration dynamic membranes of various pore sizes, J. Membr. Sci. 143 (1998) 65-73.

[19] R. Jiraratananon, D. Uttapap, C. Tangamornsuksun, Self-forming dynamic membrane for ultrafiltration of pineapple juice, J. Membr. Sci. 129 (1997) 135-143.

[20] H.M. Anderson, G.K. AI-Malack, Use of $\mathrm{MnO}_{2}$ as a dynamic membrane with crossflow microfiltration: slow membraning technique, Desalination 109 (1997) 15-24.

[21] V.M. Correia, S.J. Judd, Examination of the permeability dependence on ionic strength of low-pressure dynamically-formed membranes, J. Membr. Sci. 116 (1996) 129-139.

[22] S.C. George, S. Thomas, Transport phenomena through polymeric systems, Prog. Polym. Sci. 26 (6) (2001) 985-1017.

[23] C.H. Lu, C. Xu, Pervaporation separation of water-alcohol through chitosan/poly(sodiumacrylate) composite membrane, Shuichuli Jishu 22 (2) (1996) 75-79.

[24] C.X. Chen, B.B. Han, R. Wickramasinghe, Pervapoartion and Vapor Permeation, Chemical Industry Press, Beijing, 2004.

[25] C.H. Lu, C. Xu, M.T. Ding, B. Zhuang, Studies on the pervaporation behaviours of chitosan/sodium alginate polyionic complex membranes, J. Funct. Polym. 9 (3) (1996) 383-389. 